\title{
Tres generaciones de mujeres, tres generaciones de cuidados. Apuntes sobre una etnografía moral
}

\author{
María Teresa MARTÍN PALOMO \\ Universidad Carlos III de Madrid \\ Departamento de Sociología, Facultad de Ciencias Sociales y Jurídicas \\ mtmartin@polsoc.uc3m.es
}

Recibido: 09-07-2012

Aceptado: $17-12-2012$

\begin{abstract}
RESUMEN:
El estudio de los cuidados prestados en los entornos familiares se ha convertido en un tema de gran actualidad en el contexto del incremento creciente de la participación de las mujeres en el trabajo remunerado, de la reducción de las atribuciones del Estado de bienestar y del envejecimiento de la población en las sociedades modernizadas. En este artículo se presentan algunas reflexiones sobre la investigación de corte etnográfico realizada en la provincia de Sevilla (España), en la que se estudia la forma en que interactúan las diferentes dimensiones (material, moral y emocional) que operan en la transmisión intergeneracional de saberes y competencias sobre los cuidados que se prestan en los entornos familiares.
\end{abstract}

Palabras clave: cuidados, género, generaciones, sociología moral

\section{Three generations of women, three generations of care. Notes from a moral ethnography}

\begin{abstract}
Caregiving in families has become a topic of great interest in the context of the increasing participation of women in paid work, atributtions reduce the welfare state and the aging population in modernized societies. This article presents some reflections on an ethnographic research conducted in the province of Seville (Spain), in which we study how interact different dimensions (material, moral and emotional) operating in the intergenerational transmission of knowledge and skills about care provided in familiar environments.
\end{abstract}

Keywords: care, gender, generations, moral sociology

REFERENCIA NORMALIZADA: Martín Palomo, M. T. (2013). Tres generaciones de mujeres, tres generaciones de cuidados. Apuntes sobre una etnografía moral. Cuadernos de Relaciones Laborales. Vol. 31, núm.1, p.115-138.

SUMARIO: Introducción. 1. ¿Una etnografía moral? 1.1. Toda investigación tiene una historia: génesis de la etnografía. 1.2. Y un trasfondo epistemológico: la perspectiva etnosociológica. 2. Género y generaciones en los cuidados. 2.1. Cambios y continuidades entre generaciones. 2.2. Relaciones de intercambio entre mujeres. 2.3. Transmisiones intergeneracionales. 3. El mundo familiar de los cuidados: un trabajo de amor, un deber moral, un desafío. 3.1. Las actividades de cuidado: visibilidad e invisibilidad. 3.2. Responsabilidad moral de los cuidados: tensiones y dilemas. 3.3. Emociones y sentimientos en los cuidados. 4. Tejer y destejer una urdimbre... 5. Bibliografía. 


\section{Introducción}

La investigación de la que nace este texto ${ }^{1}$ parte de una vaga inquietud sobre los aspectos morales que subyacen a la provisión de cuidados en las familias, sumada a la extrañeza ante el hecho de que, pese a los cambios que se han producido en las relaciones de género en nuestra sociedad, fundamentalmente a raíz de la participación activa de las mujeres en la esfera pública, continúan siendo las mujeres quienes cuidan, dentro y fuera de las familias, tal como se ha puesto de manifiesto en las últimas décadas (véase por ejemplo, Martín Palomo, 2008b; Tobío et al, 2010). En este texto se presentan algunas reflexiones sobre una investigación realizada en la provincia de Sevilla en la que se estudia la forma en que interactúan las diferentes dimensiones que operan en la transmisión intergeneracional de saberes y competencias sobre los cuidados que se prestan en los entornos familiares (Martín Palomo, 2010).

\section{1. ¿Una etnografía moral?}

El universo de los cuidados nos resulta tan familiar que siempre parece estar rozando la invisibilidad; de hecho se trata de cuestiones vulgares (Molinier et al, 2009), que frecuentemente escapan a análisis sociológicos realizados de forma estandarizada. Es necesario, pues, idear métodos de investigación que abran nuevas vías para profundizar en su conocimiento. Así, con la intención de conocer las dinámicas que atraviesan los cuidados, se ha efectuado el estudio aquí comentado sobre tres generaciones de mujeres en una misma familia. (Martín Palomo, 2010). En él se analizan los discursos de treinta mujeres entrevistadas en torno a la transmisión de los saberes, las competencias, el sentido del deber y de lo justo, acerca de quién cuida y cómo; quién y cómo debe hacerlo; y la afectividad que impregna estas relaciones. El núcleo de la investigación bascula en torno a las percepciones de las mujeres, las estrategias que desarrollan y los dilemas morales prácticos que enfrentan en relación con los cuidados (Baterman, 2004: 391). El estudio se centra, pues, en el análisis de las representaciones que construyen las mujeres sobre lo que hacen (y no hacen) en relación con los cuidados, en qué medida se introducen

${ }^{1}$ La investigación aquí comentada es base de una tesis doctoral desarrollada bajo el paraguas de varios proyectos. El trabajo de campo se ha llevado a cabo con fondos de un convenio firmado por el Instituto de Estadística de Andalucía y la Universidad Carlos III de Madrid, Tres estudios sobre relaciones intergeneracionales en Andalucía, contrato Art. 83, directores de Investigación: Julio Alguacil y Constanza Tobío (2006-2008). Los aspectos teóricos del artículo se han trabajado en el marco de la investigación dirigida por Teresa Castro, Familias en plural: Implicaciones sociodemográficas y sociales de la creciente diversificación familiar desde una perspectiva internacional (Ref. CSO2009-11883). 
cambios en cada una de las generaciones estudiadas, qué es lo que permanece y, especialmente, qué tipo de justificaciones elaboran ellas sobre estas cuestiones. La propuesta de Patricia Paperman y Sandra Laugier (2005: 16) de realizar una suerte de etnografía moral para estudiar los cuidados se convirtió en un auténtico reto, personalmente asumido.

\subsection{Toda investigación tiene una historia: génesis de la etnografía}

La preocupación por el tema de los cuidados se fragua en un espacio colectivo de conocimiento, el Seminario Feminismos y Cambio Social en la Facultad de Ciencias Políticas y Sociología de la Universidad Complutense a fines de los años noventa. Las primeras reuniones del grupo se desarrollan en torno a la problemática de las actividades realizadas por las mujeres en la vida cotidiana y el desafío que supone encontrar herramientas teóricas y epistemológicas para estudiar el tema en su complejidad, lo que llevó a proponer, bajo el estímulo fleckeano, una revisión del concepto de trabajo (Martín Palomo, 2008a). Así, durante más de una década, los cuidados han estado presentes en los seminarios y las reuniones de trabajo del grupo, generando conferencias, tesis doctorales y diversas publicaciones (Miranda y Marugán, 2008).

Es, sin embargo, con la aproximación empírica durante el proceso de preparación y desarrollo de la Encuesta Redes Familiares en Andalucía, 2005 (en adelante, ERF), y los resultados tremendamente significativos que arroja, cuando cobra forma la idea de profundizar en el tema de los cuidados prestados en los entornos familiares desde una perspectiva micro, a través de una aproximación etnográfica.

El proyecto de la ERF se desarrolla en tres fases a lo largo de varios años. En la fase de preparación, entre 2002 y 2003, se realizaron diferentes trabajos con el objeto de diseñar un cuestionario y el modelo de recogida de datos: elaboración de un documento exhaustivo de las encuestas levantadas hasta la fecha sobre las redes familiares, los intercambios generacionales en el ámbito familiar, los cuidados, la conciliación de la vida familiar, laboral y personal, o los usos del tiempo; un estudio cualitativo de "reconocimiento del terreno", en el que se llevaron a cabo siete Grupos de Discusión, con los que se buscaba captar la génesis de los discursos ideológicos sobre las familias así como los cambios y retos que estas enfrentaban, y veinticuatro entrevistas semiestructuradas, que buscaban conocer los discursos sobre las prácticas de intercambio familiares; y, finalmente, un workshop con expertos de diferentes países donde se debatió en torno a la idea general de la encuesta.

En la segunda fase, de puesta en marcha de la ERF, trabajó un equipo interdisciplinar durante más de dos años, entre 2003 y 2005. Se diseñó un cuestionario que se aplicó con un microordenador de bolsillo y que fue probado en diferentes momentos (para conocer su funcionamiento, su aplicabilidad y su duración). Revisado el cuestionario tras estas pruebas, se realizó un pretest de la encuesta, con el que se simuló el funcionamiento del modelo de trabajo en red. El trabajo de campo tuvo lugar entre los meses de enero y junio de 2005. En total se entrevistó a 10.000 personas en toda Andalucía con una muestra extraída del Padrón de Habitantes. Se 
aplicó, por lo tanto, a individuos y no a hogares, y en ello radica buena parte de la originalidad y de la riqueza, pero también de la complejidad y de las dificultades de la encuesta (Fernández Cordón y Tobío, 2006)

En la tercera fase, en la que se inserta la investigación aquí comentada, se diseñó un plan de publicaciones que incluía realizar monografías y trabajos de investigación a partir de la ERF. En 2006, se presentó una propuesta para llevar a cabo un estudio complementario, una etnografía sobre tres generaciones de mujeres en una misma familia y su relación con los cuidados (véase nota 1, supra), que se desarrolló en 2006 y 2007. Para dicha etnografía se elaboró una tipología con la que seleccionar los perfiles de mujeres de tres generaciones, que permitiera profundizar en los aspectos diacrónicos de los cuidados que, a modo de fotografía, quedaron plasmados en la explotación de la Encuesta ${ }^{2}$. En total se entrevistó a diez tríadas completas, más de cuarenta y cinco horas de grabación. La monografía vio la luz a fines de 2010 (Martín Palomo, 2010).

\subsection{Y un trasfondo epistemológico: la perspectiva etnosociológica}

El diseño del estudio sobre tres generaciones de mujeres se inspira en las propuestas epistemológicas de la Grounded Theory o Teoría Fundamentada (Glaser y Strauss, 1967). Algunas de sus recomendaciones han resultado muy sugerentes para orientar el plan de trabajo, concretamente, la idea de intentar descubrir lo general entre las formas particulares, e incluso ha servido para afianzar el desarrollo de nuevas nociones o herramientas conceptuales. Pero, finalmente, no ha sido éste el marco desde el que se ha desarrollado esta investigación, más ecléctica y moderada en su ambición, que lo que dicha teoría propone. Son, sobre todo, las orientaciones marcadas por la perspectiva etnosociológica las que han guiado el estudio. En esta perspectiva, los testimonios desempeñan funciones muy distintas a las de los datos estadísticos (que ofrecen descripciones fiables de fenómenos sociales y verifican hipótesis). Se pretende mostrar cómo funciona un determinado mundo o situación

${ }^{2}$ Para conocer la incidencia de los modelos de tríadas se realizó una explotación ad hoc de los datos de la ERF. Los modelos diseñados a partir de tres variables de clasificación: actividad, clase social y posición familiar. Se entrevistó, en forma de conversaciones abiertas, a diez mujeres que colaboraron en la encuesta, a sus madres y a una de sus hijas adultas, o bien a una hija y a una nieta adulta, según la vía de contacto elegida. Para efectuar el trabajo de campo, se adoptaron las siguientes decisiones metodológicas: entrevistar a mujeres adultas de tres generaciones de una misma familia siguiendo el eje de filiación femenino; y proponer a las mujeres seleccionadas que participasen en el proyecto y que, a su vez, implicasen a su madre y a su hija, o a su hija y a su nieta. El estudio se ha limitado a aquellas tríadas cuyas integrantes residían en la provincia de Sevilla. Todos estos requisitos, en principio, se perfilaban como un reto: no parecía sencillo lograr que tres mujeres de una misma familia de diferentes generaciones estuvieran dispuestas a colaborar en la investigación propuesta. No obstante, el trabajo de campo se desarrolló sin apenas dificultades. 
social mediante una descripción más detallada, articulando hipótesis y propuestas de interpretación de los fenómenos observados (más que propuestas de explicación). También se diferencia del proceso hipotético-deductivo en el estatuto de las hipótesis, ya que no se trata de identificarlas sino de elaborarlas a partir de los elementos que se pueden observar y analizar y que permiten comprender cómo funciona (Bertaux, 2005: 23-30). Y ello empuja, igualmente, a avanzar en la reflexión teórica. De hecho, el estudio aquí presentado ha contribuido en gran medida a realizar una revisión del concepto de trabajo, y ha animado a plantear la propuesta de domesticarlo (Martín Palomo 2008a). Durante el desarrollo de la investigación ha habido una cierta circularidad y una retroalimentación muy positivas entre el trabajo de campo, las herramientas analíticas y la reflexión teórica.

La elección de un método particular para hacer un estudio sociológico tiene sus implicaciones, en tanto que compromete a quien investiga con la decisión tomada, pues inevitablemente contiene unas formas de pensamiento y excluye otras. El relato de vida es un instrumento precioso para adquirir conocimientos prácticos siempre que sea orientado hacia la descripción de las experiencias vividas por la persona entrevistada y los contextos en que esas experiencias se han desarrollado, como relato de prácticas (Bertaux-Wiame et al, 1988: 62), entendiendo que cualquier experiencia vivida encierra una dimensión social (Schütz y Luckmann, 1977). Para el análisis de los cuidados prestados por las mujeres de diferentes generaciones en las familias, este relato se traduce en una descripción de la acción en la situación concreta (por ejemplo, en torno al acontecimiento que supone el nacimiento de un hijo, al responder a la pregunta: ¿cómo hacía usted para atender a su hijo recién nacido?, ¿cómo lo alimentaba?, etc.), así como de los dilemas que enfrentan o que han enfrentado en algún momento de sus vidas. Para ello se perfiló una pauta que permitiera canalizar los principales acontecimientos vividos por la persona entrevistada en relación con los cuidados. Pero el relato de vida se basa en una combinación de preguntas y exploraciones en un contexto de diálogo con la persona entrevistada. En este diálogo la investigadora llega a conocer, al menos en parte, lo previsto; pero también puede suceder lo imprevisto, como a menudo ocurre, sobre todo a partir de aquella información que emerge desde el punto de vista de la persona entrevistada sobre su propia vida (Thompson, 1993: 70). Así, en la evolución del trabajo de campo tuvo lugar un desplazamiento progresivo de la atención hacia lo simbólico: valores, representaciones y emociones.

\section{Género y generaciones en los cuidados}

Uno de los primeros trabajos en que se aborda el estudio de las relaciones entre generaciones, es el panel sobre tres generaciones de una misma familia en Puerto Rico y EEUU a través de cuyos datos se pretende analizar el cambio cultural y familiar (Hill, 1970). Sin embargo, la mayor parte de los estudios posteriores se han limitado a comparar dos generaciones y, generalmente, se han centrado en los miembros más jóvenes, con la más que notable excepción de los estudios realizados 
por Claudine Attias-Donfut (Attias-Donfut, 2000; Attias-Donfut et al, 2003, 1998) y por Julia Brannen (Brannen, 2003, 2006).

\subsection{Cambios y continuidades entre generaciones}

El trabajo coordinado por Reuben Hill (1970) se centra, por un lado, en cuatro microconceptos a partir de lo que observa en las familias: el encierro de las mujeres en el hogar, la autoridad paterna, el control de la dimensión familiar y la indisolubilidad del vínculo matrimonial; por otro lado, en el análisis de cinco tipos de comunidad, categorización que va de rural a urbana. A partir de esta definición, realiza diferentes incursiones en el terreno: un examen rápido de los censos y de las estadísticas especializadas, el desarrollo de entrevistas dirigidas intensivas y la observación participante. Mediante estas aproximaciones obtiene material empírico centrado en el estudio de tres parejas diferentes de un mismo linaje familiar y, considerando que la generación intermedia es la que ha conocido tanto a la generación mayor como a la joven, ésta se constituye en el punto de referencia ideal para verificar el testimonio tanto de los más jóvenes como de los mayores. Además, en este estudio se incorpora un análisis contextual-histórico de cada una de las generaciones, de modo que las características básicas de los tres períodos históricos, con su diferente nivel de desarrollo social y económico, están presentes en el análisis de las generaciones consideradas (por ejemplo, lo que supone contar con recursos materiales en la vida cotidiana como electricidad, agua corriente, o ciertos electrodomésticos). Para cada uno de los conceptos-problemas analizados, una generación puede entrar en la clasificación como "tradicional", "en transición" o "moderna" (Hill, 1970: 88-89). Se analizan semejanzas y diferencias entre generaciones en la continuidad profesional, las relaciones amorosas y las prácticas de educación de menores, poniendo de manifiesto que los cambios en las normas son más marcados que los que se producen en las actitudes. En este sentido, la propuesta de R. Hill ha sido especialmente sugerente para el diseño del trabajo de campo del estudio aquí comentado.

\subsection{Relaciones de intercambio entre mujeres}

Los trabajos coordinados por Attias-Donfut en la década de 1990 han sido también un referente para el diseño de la investigación aquí presentada. La encuesta de tres generaciones de un mismo linaje familiar (hombres y mujeres) puso de manifiesto el papel esencial de las relaciones entre mujeres de diferentes generaciones en el mantenimiento de la vida cotidiana (Attias-Donfutt, 2000; Attias-Donfut y Segalen, 2000). A partir del análisis de las interacciones entre los hombres y mujeres en la vida familiar en la Francia de principios del siglo XXI, una obra más reciente, llega a la conclusión de que en la actualidad, probablemente más que en ningún otro momento histórico, las relaciones intergeneracionales están desempeñando un papel esencial (Attias-Donfut et al, 2003). De hecho, se destaca que las relaciones de intercambio entre generaciones de mujeres están siendo fundamentales en las familias, especialmente en la Europa meridional, a raíz de los cambios que se han desencadenado con la incorporación generalizada de mujeres de clases medias al 
mercado laboral en las últimas décadas, a la par que hay que dar respuesta a las necesidades de cuidados de una población cada vez más envejecida, niños, enfermos y otras personas en situaciones frágiles.

Un considerable número de trabajos dan cuenta de los intercambios y transferencias entre generaciones tanto de dinero, bienes materiales y servicios, como de bienes culturales. Estas investigaciones visibilizan el importante papel desempeñado por las redes de ayuda entre mujeres, especialmente entre mujeres de diferentes generaciones de una misma familia. También en los discursos de las entrevistadas se han identificado relatos de prácticas que dan cuenta de la gran intensidad de intercambios en relación con los cuidados, se trate de reciprocidades o solidaridades que operan con una la lógica de don-contra-don (Tobío, 2008). Es lo que narra una de las madres entrevistadas en el estudio aquí comentado, que cuidó de una tía, postrada en la cama hasta su muerte, durante más de cuatro años:

Me decía mi marido cuando se murió mi tía, dice que yo cuando me puse yo de parto... cuando me ponía yo de parto llamaba yo a mi madre, y cuando eso digo: «nos vamos ya para Sevilla que estoy para parir». Y, la primera que se metía en el coche era mi tía a la vera de mi madre. Y, mi marido cuenta él, dice: «¿qué hago yo ahí de parto con tu madre y tu tía?». Estaba con las dos. Por eso te digo que ella ha sido muy buena con nosotros, y claro, yo lo he hecho por... vamos, lo he hecho por ayudarle a mi prima, pero la consideraba, hombre, no como mi madre, pero casi. Porque ha estado con nosotros en todos los momentos. Lo mismo eso que cuando se ha muerto mi padre... lo mismo en momentos de dolor que de alegría, porque el parto es alegría, ¿no? [risas]. Y, ella ha estado con nosotros.

(Madre, E26).

Asimismo, se ha destacado que estos sistemas de intercambios y "solidaridades" intrafamiliares tienen su parte oscura, en tanto que los altos niveles de solidaridad familiar no suponen necesariamente un mayor bienestar ni para quienes prestan ni para quienes reciben cuidados (Agulló et al, 2012) e incluso pueden generar conflictos o estar teñidos por la violencia (Martín Palomo, 2010). Confrontaciones que contribuyen a definir para cada generación qué se entiende por cuidado, al menos, por buen cuidado. Esto se pone en evidencia en los puntos de vista diferentes que mantienen dos entrevistadas, madre e hija, sobre cómo entienden el cuidado de la abuela. La nieta, considera que el mejor cuidado es aquel que fomenta una mayor autonomía de la abuela; la madre, por temor a que pueda caerse o tener un accidente la protege en exceso, considera que ella debe hacer todo por su madre, como esta lo hizo todo por ella, lo que, además de convertir en aún más sacrificado el cuidado, implica que la abuela puede perder autonomía, según el criterio de la nieta. Esta disputa se destila de los párrafos que siguen:

Yo no padezco de nada, yo como lo que me ponga mi hija y todo me sienta divinamente, ahora las rodillas las tengo... La artrosis, la artrosis que tengo en la rodilla, que 
tengo la rodilla hinchada. [...] Que yo tengo que irme a mi casa la tengo yo abandonada, ¿eh? [...] Y mi hija me dice: "tú qué te vas a ir, tú te quedas aquí".

(Abuela E19,)

Aquí, en la casa, ¿con quién vive?

Ya con mi marido y mi madre, que está, para ella, provisional, porque con 90 años le dio un ictus cerebral y ya me la tuve que traer para acá el año pasado. El día siete hizo un año, de enero, ha hecho un año. Pero para ella, que cuando se le pase se va a su casa. Lo quiere así y ya está.

Ella lo quiere así y....

Tiene su casa abierta, vamos a su casa, a ver lo de allí, tiene todo allí, va a darle una vueltecita casi todas las semanas y después pues..., pero está aquí. Con noventa años ya no quiero que esté sola.

(Madre, E20)

Porque mi abuela está más torpe desde que está viviendo aquí. Pienso que tanto cuidado a veces no beneficia: «no te le levantes, que yo te lo traigo...». No, levántate, y vete para allá, que va a ser para lo poco que te vas a mover.

¿No estás de acuerdo con que tu madre proteja tanto a tu abuela?

No creo que la haga..., tanta protección.

¿Lo has hablado con tu madre?

Sí, bueno, día a día [risas].

¿Y ella qué dice?

Que nada, que no, que todo el mundo le dice lo que tiene que hacer, y yo le digo: «haz lo que tú quieras, yo te digo lo que opino». Yo pienso que le da más cuidados de los que necesita, y las cosas en exceso, no, ni en exceso ni en defecto.

¿Por qué crees que lo hace tu madre?

Porque, a lo mejor, piensa que así le evita problemas, le evita levantarse, le evita... Y, a lo mejor, el "le evita" es precisamente el perjudicarle.

(Nieta, E21)

Las entrevistadas de todas las generaciones estudiadas son conscientes de cómo funcionan estos sistemas de intercambio y apoyo mutuo, sus ventajas y sus servi- 
dumbres, cuentan con ello en su día a día, como también está presente en sus proyecciones de futuro, sea porque tienen intención de ser madres, sea porque piensan en su vejez o porque tienen presente la posibilidad del accidente o la enfermedad. Todas ellas sopesan y valoran sus recursos presentes y futuros, estudiando en detalle con qué y con quién podrán contar; se esfuerzan en construir, mantener y reforzar estos lazos, y cuidan de ello en sus vidas cotidianas ${ }^{3}$. Así, frente a las presiones que sufren, han sufrido o prevén sufrir en el futuro es difícil encontrar en las más de mil páginas de transcripciones de las entrevistas realizadas, palabras que aludan a la exigencia, al chantaje o al sufrimiento que estas situaciones podrían generar en muchas ocasiones; es más fácil hallar expresiones que se refieren a estos cuidados en términos de afectos, de un deber que se asume con gusto, por ese familiar con el que mantienen unos lazos estrechos. Sí se encuentran expresiones que dan cuenta de la tensión vivida entre demandas de los otros y el cuidado propio, pero esto ocurre sobre todo en los discursos de las entrevistadas de la tercera generación. Se recuerdan con detalle aquellas ocasiones en las que se ha recibido apoyo y se espera poder hacer lo mismo cuando otra persona de la familia se encuentre con la necesidad. Por ejemplo, cada una de las nietas entrevistadas "sabe" que su madre será un apoyo fundamental si tiene hijos algún día, o si ha vivido la experiencia de maternidad. También las madres saben que ayudarán a sus hijas cuando lo necesiten, esperan este momento en su agenda vital, las ayudan o las han ayudado. Del mismo modo que las abuelas saben que las cuidan sus hijas, sus nietas, sus nueras, o bien que les proveen de cuidadoras, y coordinan sus cuidados (Dammame, 2011), o lo harán más adelante si tienen necesidad de ello. Y este "saber" está cargado de afectos y de valores, así como de responsabilidades y obligaciones.

\subsection{Transmisiones intergeneracionales}

Las transferencias intergeneracionales se producen en tiempos concretos y están condicionadas tanto por los contextos históricos, por el ciclo de vida, como por la provisión generada desde los sistemas públicos. Además, las condiciones históricas están marcadas por las culturas del dar y del recibir que evolucionan a través de las generaciones. En un estudio reciente, Julia Brannen describe como las transferen-

${ }^{3}$ La aproximación cualitativa realizada para preparar la encuesta ERF puso de manifiesto que, en este aspecto, hay una importante diferencia de género. En un GD realizado con abuelos en Jaén en 2002, éstos daban por supuesto que serán cuidados en el futuro, cuando tengan necesidad de ello, y no manifestaron ninguna preocupación por quién o cómo se prestarían estos cuidados; sin embargo, en un GD realizado en la misma época en Córdoba con abuelas, éstas mostraron una enorme inquietud y preocupación, expresando tanto su temor a terminar sus días en un geriátrico (en el mejor de los casos, asumido con estoicismo) como a sobrecargar a sus hijas con sus cuidados. Se trata de un dilema de difícil solución pues no quieren ninguna de las dos posibilidades y, sin embargo, no encuentran otra opción, sobre todo cuando las familias no cuentan con recursos económicos para recurrir al mercado. 
cias de recursos económicos, servicios y cuidados juegan papeles distintos en el curso de la vida cotidiana, para cada una de las generaciones estudiadas, en respuesta a las necesidades particulares (Brannen, 2006: 138-140). No obstante, estas necesidades están sujetas a una continua (re)definición social y a procesos de negociación (Finch, 1989). Tal como puso de manifiesto Jean Claude Kauffman (1999), y se ha podido constatar en los discursos de las entrevistadas, hay actitudes de los hombres de la generación de las abuelas, aceptadas por estas, que tendrán que recogerlo después como parte de sus obligaciones, por ejemplo, dejar la ropa sucia en el suelo del cuarto de baño tras el aseo, que ahora son absolutamente inaceptables para las mujeres de la generación de las madres o nietas. También se encuentra inaceptable una entrega a los otros que se considera excesiva, como un modelo de amor de madre que supone ya, en cierto modo la pérdida de los límites de sí. Los cambios en los modelos implican negociaciones de cómo va a ser la nueva forma de hacer y organizar las cosas, y a quién le corresponde hacer qué. Y donde hay negociación, hay posibilidad de conflicto, sea entre mujeres y hombres, sea entre mujeres de diferentes generaciones, las tensiones entre los diferentes modelos de feminidad están relacionadas con las diferentes culturas del cuidado.

Las transferencias de recursos en las familias representan un importante aspecto del cambio y la continuidad intergeneracional según argumenta Brannen. En este análisis, el concepto de cultura ${ }^{4}$ aporta luz en el estudio de las obligaciones familiares y de las diferentes influencias de aquellas sobre las trasmisiones, materiales, culturales, o simbólicas. Esta autora diferencia entre culturas familiares que prevalecen y se trasfieren a lo largo del tiempo y culturas familiares que cambian a través de las generaciones. Los diferentes valores que adoptan tienen, a su vez, consecuencias sobre las actitudes respecto a las obligaciones familiares, qué se considera obligación familiar y qué le corresponde hacer a cada miembro (Brannen, 2006: 140-141).

En las culturas de la continuidad, los intercambios familiares generalmente se van acomodando en el tiempo, adoptando la forma de reciprocidades entre individuos específicos y, habitualmente, a través de líneas de género (Brannen y Nielsen, 2003). Las mujeres proveen de cuidados, y de las culturas sobre los cuidados, generalmente en la forma de la incondicionalidad, es decir, que los recursos se traspasan sin cálculo 'racional' de expectativa de retorno, en términos de amor y de afectos (Brannen, 2006: 141-142). Aunque esta expectativa de retorno está implícita en las propias reglas del juego de los intercambios que se mantienen en la red

${ }^{4}$ En las Ciencias Sociales se concibe la cultura como un complejo que incluye el conocimiento, las creencias, el arte, la moral, el derecho, las costumbres y hábitos adquiridos por los individuos en tanto que miembros de la sociedad y que se transmiten de generación en generación. (Es la clásica definición de Edward Burnett Tylor; cfr. Giménez, 1998: 167169). 
familiar, como ocurre con las culturas del don, muchas veces permanecen invisibles hasta que su ruptura hace emerger el conflicto latente, así como la regla que subyacía y que permitía mantener el orden social.

Esto se pone claramente de manifiesto en las reflexiones de algunas entrevistadas abuelas sobre la posibilidad de ser cuidadas por sus hijas en un horizonte no muy lejano si no pueden valerse por sí mismas en su vida cotidiana. Consideran esta suerte de contraprestación como una obligación que se genera en un intercambio justo, en tanto que ellas han cuidado de su descendencia o de otros miembros de su familia. Sin embargo, se acepta que los tiempos han cambiado y las mujeres (madres) que se proyectan en un futuro próximo como necesitadas de cuidados también son conscientes de que los condicionantes que tienen (y que previsiblemente tendrán) sus hijas no les permitirán poder hacerse cargo de su cuidado como ellas hicieron con sus propias madres o abuelas.

Las culturas de la discontinuidad, que se expresan en una mayor independencia o distancia entre los diferentes miembros de la familia, generalmente son características de familias que han experimentado gran movilidad social y geográfica a raíz del acceso generalizado a la educación y al trabajo remunerado en la segunda o la tercera generación, depositando gran parte del soporte de los cuidados en el Estado proveedor y/o en el mercado. Probablemente es en las culturas de la discontinuidad donde es posible observar con más claridad cómo se negocian y renegocian la reglas del intercambio intragénero y entre generaciones. Es difícil saberlo a partir de la investigación realizada ${ }^{5}$, aunque todo parece indicar que es así. Por ejemplo, tal como se vio más arriba, el concepto de cuidado, varía enormemente de la madre y la nieta respecto de la abuela (véase verbatim citado más arriba, E.19, E.20 y E.21).

La gran diferencia estriba en qué puede ser considerado como cuidado de calidad, si aquel que proporciona la posibilidad de mantener durante más tiempo la autonomía, o aquel que pretende proveer de todo lo que necesita la persona cuidada, independientemente de que esta pueda asegurar parte de su autocuidado por misma. El primer modelo, prevalece entre las entrevistadas más jóvenes, sobre todo las nietas, y el segundo entre las madres y abuelas, que tienen un concepto más sacrificial del cuidado de sus familiares o, al menos, es posible identificar más tensiones entre las exigencias del cuidado de los otros con el cuidado de sí mismas que entre las más jóvenes. Las mujeres de la segunda generación (que están cuidando de sus progenitores, hijos y a veces nietos) tienden a ponerse a sí mismas más entre paréntesis, con sólo tímidas reivindicaciones del cuidado propio.

${ }^{5}$ Por el propio dispositivo de captación, en esta investigación no ha sido posible entrevistar a tríadas en las que el vínculo estuviera roto o muy deteriorado, o fuera laxo, ya fuese debido a los conflictos entre algunas de sus integrantes, la distancia o cualquier otro motivo. 
Pero yo pienso que su generación es la cuidadora de las cuidadoras, o sea que realmente quienes cuidan a los mayores, cuida a los jóvenes. Mi generación yo la veo yo desde otro punto de vista.

(Nieta, E9)

También nos ha tocado a los abuelos, es que a nosotros nos ha tocado vivir en una época muy mala [risas].

¿Les ha tocado cuidar de todos?

Ahí, ahí, ahí, nos ha tocado cuidar de los padres, cuidar de los hijos, para que ustedes se forméis y eso, y luego cuidar de los nietos para que ustedes sigáis trabajando, con que esa es la época que nos ha tocado vivir a los de los cincuenta [risas]. ¿A que sí? ¿A que es así?

SÍ.

Así es. Pero no es la mejor, vamos, no es la mejor, ¿eh? Pero que aún así, yo quiero vivir muchos años como estoy ahora mismo para ayudarles mucho, seguir ayudándoles muchos años; así pienso, ayudarles en todo lo que pueda. La he ayudado a ella y ayudaré también a sus hijos, si los tiene, y cuidarlos y hacer lo que pueda y seguiré ayudándola a ella, ¿a ver qué? Si quiere venir a comer, que venga y ya está.

(Madre, E8).

Entre las entrevistadas, ha sido más frecuente encontrar el modelo de continuidad que el de ruptura, aunque se detecten elementos de continuidad y cambio en diferentes generaciones en las prácticas y en los discursos en torno a los cuidados. Como se argumentará a continuación, todo ello tiene mucha relación con los aspectos afectivos y morales.

\section{El mundo familiar de los cuidados: un trabajo de amor, un deber moral, un desafío}

Los cuidados se han conformado como un campo de investigación a lo largo de la última década pese a no haberse consensuado aún qué se entiende por cuidado(s). Hay cierto acuerdo en que se trata de un trabajo y que es fundamental “...para mantener, perpetuar y reparar nuestro «mundo», de manera que podamos vivir en él lo mejor posible" (Tronto, 2009, p. 13). Pero las definiciones más clásicas son muy restringidas y las más amplias resultan demasiado genéricas. Se apunta que aún queda mucha elaboración teórica por hacer en el campo de la sociología y que dicha elaboración debe ir de la mano de estudios empíricos de diferente calado realizados con una perspectiva de género. El carácter relacional e invisible, así como la transversalidad de los cuidados, hacen que sea un ámbito de estudio muy escurridizo. 
Pero analizar los cuidados en el entorno doméstico-familiar presenta aún una mayor complejidad (Martín Palomo, 2008b). Una propuesta que facilita su análisis es considerar en la vida familiar tres dimensiones: afectiva, moral y material (Parreñas, 2001: 117). La primera entroncaría con la dimensión emocional de las relaciones familiares: la calidad humana, la preocupación por el otro, la compasión, el amor; pero también las tensiones, los chantajes, los conflictos e incluso la violencia. La segunda se refiere al sentido de lo bueno, lo justo y lo adecuado, engloba tanto cuestiones disciplinarias como de socialización de los menores y la responsabilidad que conlleva, con una implicación que puede ir de la abnegación y el sacrificio hasta el abandono. Y, la tercera hace referencia a todo relacionado con la oferta y el consumo de servicios dentro del hogar. Pese a haberlos desagregado aquí por necesidades de análisis, no es tarea sencilla distinguir cada dimensión ni diferenciar el trabajo doméstico respecto de los cuidados, en tanto que operan simultáneamente. No obstante, este esquema ha sido revisado con más detalle en otros trabajos (véase por ejemplo: Martín Palomo, 2008a, 2010).

\subsection{Las actividades de cuidado: visibilidad e invisibilidad}

En general, la dimensión material de los intercambios permite que estos sean cuantificables tanto en términos de tiempo como de dinero y, por tanto, se puede estimar mediante diferentes métodos (Durán, 2012). Sin embargo, es sumamente complicado medir los tiempos en los cuidados en tanto que, por un lado, a menudo se desarrollan de forma simultánea con otras actividades: y, por otro lado, tienen mucho de anticipación, de disponibilidad y de preocupación a la vez que, para que sea un cuidado de calidad, tiene que ser discreto y poco, o nada, visible (Molinier, 2005). Los diferentes métodos de medida poseen grandes limitaciones para analizar aspectos como la simultaneidad de tareas, la disponibilidad, la anticipación, la preocupación por el otro, los afectos o la responsabilidad. Estas limitaciones tienen relación con el hecho de que en el ámbito doméstico se da un tipo de vínculo muy específico entre las personas: la disponibilidad del tiempo de las mujeres al servicio de los miembros de su familia (Fougeyrollas-Schwebel, 2002: 175-178). Este aspecto se destaca en la siguiente locución:

Yo tengo mucho avío con mis hermanas, pero cada una está en su casa. Entonces yo, que ahora mismo llega mi marido y me dice: «Pues vamos aquí o allí». Pues, yo tengo que decirle a mi hermana: «Mira, vente que voy a aquí o allí». Y, tengo que plantear comida, que no es como la que está en su casa y dice: «Me voy, me quedo, me voy». $\mathrm{Y}$, yo que soy de poco salir y tengo el amarre de mi madre, pues no salgo.

(Madre, E25)

$Y$ es que, tal como se señala en otro lugar, gran parte de las actividades de cuidados son contingentes, dependen de las demandas de los otros (Martín Palomo, 2008a: 23-24) y, ya se realicen de forma simultánea, ya secuencial, requieren de una dedicación constante (Ramos, 1994: 53). Las actividades tienen el sentido que le asignan las personas que las realizan, por lo que tanto los tiempos, como las 
actividades mismas, son más complejos que la simple duración. Por ello es tan complicado dotar de visibilidad a los cuidados así como su medición y valoración, sobre todo a partir de instrumentos estandarizados de recogida de datos (Legarreta, 2008). Frecuentemente, los cuidados se prestan a la par que se desarrollan otras actividades, en las que, como se ha señalado más arriba, la preocupación y la anticipación juegan un papel fundamental, requieren de un saber discreto, de escasa visibilidad. Por eso, Pascale Molinier afirma que los cuidados sufren un déficit crónico de reconocimiento ordinario (2005: 299-301). En tanto se da por supuesto, no se ve, lo que provoca malestar a quienes cuidan habitualmente, como dice una entrevistada madre, respecto del distinto rasero con que su suegra mide la atención proporcionada por sus hijos e hijas durante una estancia hospitalaria:

Porque es que mi suegra, me hacía gracia porque decía: «jay! a mí me da lástima». Cuando se quedaba su hijo le daba mucha pena porque al otro día iba a trabajar, cuando se quedaba mi marido por la noche. Y, y le decía mi cuñada: «hombre, de mí no te da lástima porque yo voy a trabajar lo mismo que tu hijo, yo voy lo mismo, yo me tengo que ir a las siete de la mañana, igual que tu hijo». Y, a ella le daba lástima de sus hijos [risas], y luego ella iba a trabajar igual, vamos, por eso te digo que, que es cuestión de..., bueno...

(Madre, E17)

\subsection{Responsabilidad moral de los cuidados: tensiones y dilemas}

La dimensión moral de los cuidados hace referencia al sentido normativo de la responsabilidad de los mismos, que se expresa cotidianamente en las tensiones y dilemas existentes en su provisión. Pese al aparente carácter abstracto de estas cuestiones, se trata de disyuntivas muy concretas, formas de enfrentar, sopesar y decidir (o no) sobre cuestiones candentes de la vida cotidiana que tocan de una forma u otra a todas las personas: en tanto seres sociales, el vínculo social atraviesa principios morales últimos que orientan nuestro comportamiento. Dichos principios son aquellas ideas, valores, razonamientos, normas, por las cuales las personas actuamos o creemos que debemos actuar, es decir, aquellas construcciones que definen lo que está bien y lo que está mal, lo que consideramos correcto, lo que nos parece justo y adecuado para una vida buena (Martín Palomo, 2008a: 27). Atraviesan la vida cotidiana de todas las personas, ya que todo ser humano tiene que decidir qué conducta seguirá, qué va hacer con su vida. Y, al escoger entre distintos cursos de acción posibles, se encuentra en la necesidad de justificar -ante sí y ante el mundo-, de explicar (aunque sea tácitamente) por qué ha optado por ese determinado comportamiento. Estas explicaciones son en sí mismas descripciones morales (Pharo, 2004a, 2004b). En el discurso de las entrevistadas se han rastreado dichas justificaciones y la forma en que éstas construyen la explicación del sentido de su acción, así como la forma en que expresan sus dilemas y contradicciones. Para las tres generaciones estudiadas, estas justificaciones permanecen vinculadas a construcciones de un deber ser "mujer", que liga los cuidados con la condición femenina. Así, por ejemplo, se considera que es "natural" que unas mujeres de la familia 
ayuden a otras, sobre todo que las madres ayuden a las hijas en el cuidado de las criaturas recién nacidas o cuando son aún pequeñas:

...cuando nació mi hija me venía aquí a Sevilla como es natural con mi hija para que me... con mi hija, digo yo, con mi madre, para que me ayudara. Y, estaba con ella, después me tenía que ir yo para el pueblo con la niña.

(Abuela, E1)

Hablar de lo "natural" en moral puede sugerir que no es posible el cambio. Sin embargo, nuestros conceptos morales no son estáticos, ni se aplican de forma mecánica a la realidad, sino que dependen de la descripción que damos de nuestra existencia así como de lo que es importante para nosotros en la vida ordinaria; se negocian y se recrean constantemente (Paperman y Laugier, 2005: 15-16), muchas veces de forma conflictiva. Sostiene Patrick Pharo que las normas, al igual que los valores morales, pueden ser analizadas como 'hechos sociales'. Al estudiar las posibles vías para adentrarnos en la descripción de los hechos morales, afirma este autor que hay espacios de negociación (y, por lo tanto, de conflicto) en todo lo que tiene que ver con la evaluación moral. Es decir, las formas en que los individuos en su actuar cotidiano sopesan valores, enfrentan sus conflictos y tomas de decisiones (Pharo, 2004a: 73-74), varían considerablemente de unas sociedades a otras, de unos tiempos a otros y, por tanto, de unas generaciones a otras. Al depositar la mirada en el significado y los valores que las entrevistadas dan a un determinado orden normativo de la sociedad, a lo que ellas consideran que es justo, el significado interno, y no sólo en el significado externo, como hicieran clásicos de la sociología como Durkheim o Parsons (Ibídem, 83-84), a partir del análisis de los discursos de las entrevistadas nos aproximamos a su forma de ver el mundo y a comprender sus motivos, sus razones.

En las familias se generan y transmiten valores morales. En general, cada familia es una referencia normativa y de construcción de la propia identidad para sus miembros. El valor moral atribuido a cada acción está asociado al proceso de integración social y tiene que ver con la forma de construcción de significados en normas e imágenes. Estas normas e imágenes operan en la regulación de las relaciones entre las personas en sus vidas cotidianas, es decir, aparecen como costumbres que guían el actuar cotidiano (Thiebaut, 1985: 131-136), rutinas más o menos conscientes, o expectativas de comportamiento. La conformidad con las normas sociales no siempre es consciente, e incluso el régimen de voluntad, de justificaciones, que la acompaña puede ser extremadamente débil. Parece necesario que la persona se sienta vinculada emocionalmente en la incitación normativa para que se pueda hablar de comportamiento normativizado, si no, no habría una norma que se cumple sino una cierta regularidad factual (Pharo, 2004a: 81-82). Por tanto, las emociones se integran en estas justificaciones complejizando enormemente su elaboración.

En los relatos de las entrevistadas, los valores morales aparecen en lo que se dice sobre las distintas formas de comportamiento, en la validez que se les atribuye, así como en los conflictos que emergen bajo las mismas. En sus discursos, por ejemplo, 
está generalizada la norma de que una madre debe sentir amor y sacrificarse por sus hijos e hijas. Es un mandato que no se suele poner en cuestión. Lo que sí lo está es hasta dónde debe llegar este sacrificio del tiempo propio, del autocuidado, de otros trabajos o relaciones sociales por parte de las cuidadoras, madres, hijas, hermanas, cuñadas, nueras, nietas, abuelas, y dónde se encuentra el límite, lo que ya sería "demasiado", tema del que se habla con más claridad y contundencia en la segunda y tercera generación -las madres y las nietas entrevistadas. También está en cuestión el papel que deben jugar, y que juegan de hecho, los hombres, ya sea en el cuidado de sus hijos e hijas ya sea en el de los progenitores. Muy poco se dice, además, sobre el papel que desempeñan o deben desempeñar en su autocuidado o en el cuidado de sus parejas, incluso dentro de los discursos de las mujeres más jóvenes.

Por este motivo, tal como señala Carlos Thiebaut (1987: 125-130), resulta de interés conocer: si se introducen modificaciones significativas en las formas de socialización moral en relación con las transformaciones que tienen lugar en las relaciones intrafamiliares, cómo ocurre, si la percepción de estos cambios que aparecen en los discursos sociales sobre las familias tiene (o no) efectos sobre la actuación de cada uno de sus miembros, y qué tipos de efectos tiene. Y, por tanto, su capacidad performativa. En este sentido, las mujeres en las familias continúan siendo la principal vía de transmisión de este saber cargado del sentido del deber, como se pone de manifiesto en la siguiente locución:

Sí, porque, ya te digo, soy la mayor y fui prima con ocho años y, verás, como fui una niña así muy... Según mis tíos, yo, hablaban conmigo como si fuera una persona mayor y lo entendía bien, y yo me acuerdo. Entonces, mi tía en el momento me enseñó a cambiar pañales, a dar biberones, a todo, me decía: «ven para acá, que te voy a enseñar, que es mejor saberlo antes». Y me enseñó. $\mathrm{Y}$, es verdad, porque, después, quieras que no, a lo mejor, te llevas unos pocos de años sin coger a un niño, pero yo he cambiado los pañales a $\mathrm{C} . .$. , a todos mis primos.

(Nieta, E6)

Efectivamente, a través de los discursos de las mujeres de las tres generaciones estudiadas se ha podido ver que los cambios que han experimentado las familias tienen un fuerte eco en las formas de involucrarse en el cuidado de sus criaturas por parte de los progenitores. Por ejemplo, la expectativa de comportamiento en relación con los hombres como figura de autoridad ha ido progresando hacia una mayor democratización de las relaciones de los padres con sus hijos y con sus cónyuges. Así, "ese respeto que había", del que hablan las abuelas y algunas madres entrevistadas, teñido de temor y, en ocasiones, con entreverados rastros de violencia (coacciones, amenazas, y también malos tratos físicos), pierde progresivamente vigencia como valor moral, como norma de comportamiento, para pasar a tener un mayor peso aquellos discursos sobre las relaciones más igualitarias entre diferentes miembros de las familias, hombres y mujeres pero también entre padres e hijos, y empie- 
za a cobrar valor, asimismo, la figura de los hombres cuidadores, sean padres, abuelos, parejas o hijos.

Finalmente, si bien no se analizan aquí por exceder las dimensiones propias de este artículo, hay aspectos de índole bioética que entroncan directamente con los cuidados y con los dilemas morales que se generan en torno a los mismos. Concretamente, al enfrentar aquellas situaciones vividas por quienes se encuentran en un estado de deterioro tal que se plantea la eutanasia activa o pasiva. Se trata de cuestiones que están estrechamente relacionadas con la de qué se considera que es un ser humano y qué es lo que le caracteriza, y qué se considera que es un buen cuidado.

\subsection{Emociones y sentimientos en los cuidados}

Tal como se ha señalado más arriba, incorporar las emociones al análisis de la construcción social del sentido de la acción contribuye a la comprensión de los motivos que las personas atribuimos a nuestros actos, la forma en la que explicamos nuestra acción (Iranzo, 1999: 11-22). Los momentos y las condiciones de las expresiones colectivas de los sentimientos están regulados, predefinidos, al igual que lo están tanto qué personas están obligadas a expresarlos como la intensidad con que ha de hacerse (Mauss, 1968: 81). Pero el que estos sentimientos y sus formas de expresión estén pautados, no implica que quienes los manifiestan no los sientan efectivamente.

No obstante, hasta hace unas décadas, en el campo sociológico se había prescindido de los afectos, las pasiones, los sentimientos, y ello pese a que en los orígenes de la disciplina se les concedía cierta importancia. En desarrollos teóricos posteriores, las emociones han sido tratadas, en general, de forma residual, sin considerar que tengan relevancia para los estudios sociológicos (Bericat, 2000: 146). En el año 1975, Arlie R. Hochschild publica un artículo pionero en la incorporación de esta dimensión de las emociones como vía de conocimiento de cualquier fenómeno social. Explora Hochschild la estructura emocional de la vida cotidiana de hombres y mujeres en las familias, revolucionando con ello los estudios sobre el trabajo, al poner de manifiesto que las emociones están condicionadas por normas sociales, a la par que problematiza los lazos afectivos en las relaciones intrafamiliares al preguntarse cómo se construyen y manifiestan los afectos entre sus miembros (Hochschild, 2008).

Los estudios sobre desarrollo moral realizados a partir de los años sesenta por autoras como Nancy Chodorow (1984) o Carol Gilligan (1985) incorporan las emociones, los sentimientos, al desarrollo moral. En su vertiente más esencialista, buena parte de los trabajos que desencadenan estas publicaciones, vinculan los cuidados con la expresión de la naturaleza femenina (cfr. Martín Palomo, 2008b), frente a lo cual se plantea en qué medida cuidar es, o puede ser considerado como, una labor de amor (Finch y Groves, 1983). En sus formas más problemáticas algunas de estas formulaciones encierran diferentes versiones del "instinto" maternal que tiene un gran calado en los discursos de las entrevistadas de todas las generaciones. Desde esta perspectiva se reactiva la importancia de las emociones en el estudio de los cuidados (Martín Palomo, 2008a: 24-27). En la medida en que des- 
empeñan un papel central en la construcción de la identidad femenina, analizar estos aspectos adquiere aún más sentido (Finch, 1989). Así, por ejemplo, emergen en los discursos de las entrevistadas en forma de tensión entre el peso de la posible construcción social de la maternidad y el del instinto, entre lo que se considera que es la naturaleza que impulsa y lo que es aprendido, desde las primeras instancias de socialización como deber moral ineludible, transmitido por madres, abuelas, tías y otras mujeres de la familia, pero también a través de los consejos de expertos (médicos, matronas, farmacéuticos, entre otros).

Sí, sí, sí, se aprende, sí. Te cambia mucho, o sea tú lo ves muy lejos, pero una vez que lo tienes, parece que tienes las ideas, que te viene todo ya así..., sí, sí, sí. Yo creo que te sale todo, sí. Igual que, igual que el cariño maternal que cuando ya estás embarazada ya lo vas teniendo, pues yo creo que igual las otras cosas las vas haciendo ya por instinto, por...

(Madre, E23)

Todo ello es especialmente visible cuando se trata del nacimiento del primer hijo o hija, y la forma de dar respuesta a sus necesidades de cuidado. Y es que en torno a procesos como el de amamantar una criatura, sin ir más lejos, se van incorporando progresivamente una serie de normas sobre el deber ser del cuidado de los hijos, sobre qué se entiende por buen cuidado. Ello pese a que, como se destila en los discursos de las tres generaciones estudiadas, los expertos cambian de vez en cuando sus consignas, por ejemplo, sobre durante cuánto tiempo y con qué asiduidad las madres deben dar el pecho a sus criaturas, cuándo y cómo incorporar otro tipo de alimento, u otros muchos aspectos relacionados con la crianza (baño de las criaturas, regulación del sueño, control de esfínteres, etc.). De igual modo, cambia el contenido de los consejos que las madres dan a las hijas sobre qué es lo que deben hacer cuando la criatura tiene un problema concreto de salud o de alimentación. Lo que menos ha cambiado, o se mantiene más estable a través de las generaciones, es el sujeto que adquiere la responsabilidad sobre el cuidado y el bienestar de la criatura: generalmente, es la madre quien debe encontrar su propio modo de hacer bien las cosas, mezclando las normas y los consejos que le transmiten sus madres, otras mujeres de la familia, las vecinas o los expertos, con su propio criterio (en muchas ocasiones, expresado en términos de instinto) para prestar un cuidado de calidad. Y, son las madres las que se ven obligadas cotidianamente a tomar las decisiones, siendo ellas, en último término las responsables de las mismas (y, claro está, de sus consecuencias). Si bien en muchas ocasiones comparten con sus cónyuges o parejas los problemas y dificultades que tienen, habitualmente, son infinidad de decisiones las que toman cada día, construyendo el deber ser del cuidado que se entrelaza con su identidad de madres, asumiendo que pueden cometer errores - y de hecho los cometen-, precisamente con esos seres queridos, que, sea por mucha o poca edad, o 
por su estado de salud precario presentan una enorme vulnerabilidad. Y, con esta posibilidad siempre presente de errar, el asumir la responsabilidad de los cuidados de sus familiares las hace más vulnerables ${ }^{6}$ :

¿Cómo aprendí a cocinar? A base de poner carne, albóndigas, que me daban sebo en la carnicería porque yo no sabía pedir la carne picada, o de hacer unos fideos en una cazuela de fideos con los fideos picados, porque yo no sabía que tenían bichos. Aprendes a base de..., pues, con los hijos, pues es igual, ies que tú has estudiado para ser socióloga...?

Sí.

Pero, yo [risas] para ser madre, si algún día lo eres, eso no te lo van a enseñar, ¿eh? Eso te irá viniendo el día a día y observando a tu hijo porque, además, es que lo observas las veinticuatro horas, y si duerme, porque está dormido, si respira más flojo, si respira mal, pero es que es así, y tú sola vas aprendiendo a conocerlo. Mi perra tiene doce años, al principio se me ha puesto mala del estómago y he ido al veterinario quinientos millones de veces. Ahora sé qué es lo que le tengo que dar, qué no le tengo que dar, que es lo qué le hace daño, cómo cuidarlo, si le pasa algo qué le tengo que hacer, todo lo aprendes.

(Madre, E29)

Estos discursos, llenos de ambigüedades y de dificultades, expresan intentos de articular los imperativos de los distintos modelos de feminidad y de maternidad que conviven entre sí en diferentes generaciones. Esta tensión es más clara en los discursos de las madres y las nietas entrevistadas que en las abuelas, que sostienen que el "instinto" tiene un mayor peso como explicación de las diferencias entre hombres y mujeres:

Y, el doctor Spock decía, los consejos era: «déjate guiar por el instinto, lo que te parezca, que te lo quieres meter en la cama, pues te lo metes, que lo pones en la cuna, pues lo pones, lo que te parezca a ti». Entonces, eso me confortaba. El instinto es muy fuerte y eso me ayudó."

(Madre, E2)

\section{Tejer y destejer una urdimbre...}

La invitación de Paperman y Laugier a analizar los cuidados desde una aproximación que permita estudiar de forma pormenorizada las dimensiones emocionales

\footnotetext{
${ }^{6}$ Sobre la experiencia humana vulnerable y la inevitabilidad del error, véase, Chauviré $e t$ al, 2009.
} 
y morales en el actuar cotidiano, realizando para ello una etnografía moral, es la intención que ha nutrido desde el inicio la investigación y de la que se da cuenta en estas páginas, en la que se intenta avanzar en el análisis de las múltiples imbricaciones existentes entre dichas dimensiones. Efectivamente, constituye un reto encontrar formas de dar expresión a este silencio, a esa necesidad de los cuidados, de ser discretos o apenas visibles para funcionar adecuadamente.

Al incorporar simultáneamente las dimensiones emocionales y morales, se ha buscado mostrar algunos aspectos de cómo se transmiten y negocian entre diferentes generaciones los saberes y competencias sobre cuidados, los afectos, así como la responsabilidad moral asociada a los mismos, en el propio sentido que los sujetos dan a sus prácticas, los principios en que estas se sustentan, y que las sustentan, esto es, cómo cobra forma la explicación del sentido de su acción; pero también del sentido que dan a las consecuencias de dichas acciones. Se ha intentado argumentar sobre el aspecto social y construido de dichas normas morales en base al modo en que varían de unas generaciones a otras así como sus posibilidades de trasgresión que son mayores en unos aspectos (la forma en que se cuida de una criatura) que en otros (quién tiene la responsabilidad de este cuidado).

Tal como se ha podido desgranar en el análisis de los discursos de las entrevistadas, parece muy difícil establecer la frontera entre unos y otros aspectos: se entreteje lo afectivo con lo moral de tal modo que resulta casi imposible efectuar un corte entre un tipo de aspectos y otros en la transmisión del saber, de la responsabilidad y de la afectividad que atraviesa la relación en los cuidados. Más bien se retroalimentan en la construcción de los saberes y competencias sobre los cuidados (Martín Palomo, 2010). Todo apunta a que el saber hacer, el afecto y la responsabilidad sobre el cuidado se hilan en un complejo continuum del que aún queda mucho por conocer ${ }^{7}$.

\section{Bibliografía}

Agulló, M. S., Rivero, A., Martín Palomo, M. T., Gómez, M. V. Sáiz, Rosana y Agulló, E. (2012). Análisis y evaluación de los programas para cuidadores de

${ }^{7}$ Agradezco a Carlos Prieto el interés mostrado por este trabajo y la invitación a presentar los resultados del mismo en la Jornada organizada por el Grupo de Investigación EGECO, Los cuidados, entre el trabajo y la vida, que tuvo lugar en la Facultad de Ciencias Políticas y Sociología (UCM), el 15 de diciembre de 2011. A Constanza Tobío, el respaldo prestado durante años para trabajar en esta investigación. A Gloria Martín Palomo, los cuidados prestados a mi hija Elia mientras trabajé en el artículo. A José María Muñoz Terrón, la atenta lectura y las sugerencias realizadas al texto, aunque la responsabilidad del mismo es exclusivamente mía. 
mayores. Comunicación presentada en II Jornadas de Sociología de la Asociación Madrileña de Sociología. Madrid.

Attias-Donfut, C. (2000). Rapports de générations. Transfers intrafamiliaux et dynamique macrosociale. Revue Française de Sociologie, Vol. 41, Núm. 4, 2.

Attias-Donfut, C., y Segalen, M. (1998). Grands-parents. La famille à travers les générations. Paris: Odile Jacob.

Attias-Donfut, C., Lapierre, N. y Segalen, M. (2003). Le nouvel esprit de famille. Paris: Odile Jacob.

Baterman, S. (2004). L’Expérience morale comme objet sociologique. L'Anne Sociologique, Vol. 54, Núm. 2, pp. 389-412.

Bericat, E. (2000). La Sociología de la emoción y 1.a emoción en la sociología. Papers, Vol. 62, pp. 145-176

Bertaux, D. (2005). Los relatos de vida. Perspectiva etnosociológica. Barcelona: Bellaterra.

Bertaux-Wiame, I. et al (1988). Trabajo e identidad femenina: una comparación internacional sobre la producción de las trayectorias sociales de las mujeres en España, Francia e Italia. Sociología del Trabajo, Vol. 3, pp. 71-90.

Brannen, J. (2003). Towards a typology of intergenerational relations: continuities and change in families. Sociological Research Online, Vol. 8, Núm. 2. En línea: http://www.socresonlien.org.uk/8/2/ Brannen. Html [Consulta: 28.03.2007].

- (2006): "Cultures of intergenerational transmission in four-generation families", The Editorial Board of The Sociological Review. Blackwell Publising Ltd.

Brannen, J. y Nielsen (2003). Structure, agency and notions of choice. En Kollind y Peterson (eds.). Thoughts on Family, Gender, Generation and Class. Goteborg: Goteborg University.

Chauviré, C. Ogien, A. y Quéré, L. (2009). Dyanamiques de l'erreur. Paris: EHEES, Raisons Pratiques.

Chodorow, N. (1984). El ejercicio de la maternidad. Psicoanálisis y sociología de la maternidad y paternidad en la crianza de los hijos. Barcelona: Gedisa. 
Damamme, A. (2011). El cuidado en las familias: perspectiva temporal versus radiografía. En P. Molinier y L. G. Arango (comp.). El trabajo y la ética del cuidado. Cali: La Carreta Social, pp.157-167.

Durán, M. A. (2012). El trabajo no remunerado en la economía global. Bilbao: Fundación BBVA.

Fernández-Cordón, J. A. y Tobío, C. (2006). Andalucía: Dependencia y solidaridad en las redes familiares. Sevilla: IEA.

Finch, J. (1989). Family Obligations and social Change. Cambridge: Cambridge Polity Press.

Finch, J. y Groves, D. (eds.) (1983). A labour of love: women, work and caring., Londres: Routledge.

Finch, J. y Mason, J. (1993). Negotiating Family Responsibilities. Londres: Routledge.

Fougeyrollas-Schwebel, D. (2002). Trabajo doméstico. En Hirata et al. (eds). Diccionario crítico del feminismo. Madrid: Síntesis, 175-178.

Franzkre, J. (1993). El mito de la historia de vida. Historia y Fuente Oral, Vol. 2, pp. 57-64.

Gilligan, C. (1985). La moral y la teoría: psicología del desarrollo femenino. México: FCE.

Giménez, C. (1998). Cultura. En Giner et al (coord.). Diccionario de Sociología. Madrid: Alianza, pp. 167-169.

Glaser, B. y Strauss, A. (1967). The Discovery of Grounded Theory: Strategies for Qualitative Research. Chicago: Aldine.

Hill, R. (1970). Une technique de recherché étalée sur trois générations. Nouvelle Méthode d'étude du changement familial et social. En Michel (ed.). La sociologie de la famille. París: Mouton.

Hochschild, A. R. (2008). La mercantilización de la vida intima: apuntes de la casa y el trabajo. Buenos Aires: Katz.

Iranzo, J. M. (1999). Emociones globales: la reconstrucción de una teoría de las pasiones. Política y Sociedad, Vol. 30, pp. 11-22. 
Kauffman, J. C. (1999). La ropa sucia. En U. Beck (dir.), Hijos de la libertad., México: FCE, pp.194-227.

Lejeune, P. (1994). La autobiografía de los que no escriben. En El pacto autobiográfico y otros estudios. Madrid: Endymion.

Legarreta, M. (2008). El tiempo donado en el ámbito doméstico: reflexiones para el análisis del trabajo doméstico y los cuidados. Cuadernos de Relaciones Laborales, Vol. 26, Núm.2, pp. 45-69.

Martín Palomo, M. T. (2010). Los cuidados en las familias. Estudio a partir de tres generaciones de mujeres en Andalucía. Sevilla: Instituto de Estadística de Andalucía.

- (2008a). Domesticar el trabajo: una reflexión a partir de los cuidados. Cuadernos de Relaciones Laborales, Vol. 26, Núm.2, pp.13-44.

- (2008b). Los cuidados y las mujeres en las familias. Política y Sociedad, Vol. 45, Núm. 2, pp. 29-47.

Mauss, M. (1968). L'expression obligatoire des sentiments. En Essais de Sociologie. Paris, Minuit, pp. 81-88.

Miranda, M. J. y Marugán, B. (2008). Breve Genealogía del Grupo de Investigación Feminismo y Cambio Social. Cuadernos de Relaciones Laborales, Vol. 26, Núm.2, pp. 159-161.

Molinier, P., Laugier, S. y Paperman, P. (2009). Introduction. Qu'es-ce que le care? Paris: Payot, pp. 7-31.

Molinier, P. (2005). Le care à l'épreuve du travail: vulnérabilités croisées et savoirfaire discrets. En Paperman y Laugier (eds). Le souci des autres, éthique et politique du care. París : EHESS, pp. 299-316

Muñoz Terrón, J. M. (2010). Responsividad y cuidado del mundo. Fenomenología y ética del care. Daímon. Revista de Filosofía, Núm. 49, pp. 35-48.

Paperman, P. y Laugier, S. (2005). Présentation. En Paperman y Laugier (eds). Le souci des autres, éthique et politique du care. Paris: EHESS, pp.9-22.

Pharo, P. (2004b). L'Enquête en Sociologie Morale. L'Anne Sociologique, Vol. 54, Núm.2, pp. 359-388.

- (2004a). Morale et sociologie. París: Gallimard. 
Ramos, R. (1994). El trabajo de la mujer desde la perspectiva del uso del tiempo. En Montañés et al. (eds), El trabajo desde una perspectiva de género. Madrid: Comunidad de Madrid, Consejería de Presidencia, DGM.

Salazar Parreñas, R. (2001). Servants of Globalization: Women, Migration and Domestic Work. Stanford: Stanford University Press.

Schütz, A. y Luckmann, T. (1977). La estructura del mundo de la vida. Buenos Aires: Amorrortu.

Thiebaut, C. (1987). Los valores morales en la familia española. En Beltrán, García Ferrando et al. Estudio de la Familia Española. Madrid: Ministerio de Trabajo y Seguridad Social, pp. 125-130.

Thompson, P. (1993). Historias de vida en el análisis del cambio social. En Marinas y Santamarina (eds.). Historia Oral: Métodos y Experiencias. Madrid: Debate. pp. $65-81$.

Tobío, C. (2008). Redes familiares, género y política social en España y Francia. Política y Sociedad, Vol. 45, Núm. 2, pp. 89-106.

Tobío, C., Gómez, M. V. Agulló, M. S. y Martín Palomo, M. T. (2010). El cuidado de las personas. Un reto para el siglo XXI. Barcelona: Fundación La Caixa.

Tronto, J. (2009). Préface à l'édition française. En Tronto, Joan, Un monde vulnérable, pour une politique $d u$ care. Paris: La Découverte, pp. 11-22. 